\title{
Decomposing the effects of organizational memory on marketing implementation
}

\author{
Stern Neill
}

\begin{abstract}
There is limited evidence to explain the effect of organizational memory on marketing implementation. This paper addresses this gap by identifying multiple components of organizational memory and examining how each affects marketing implementation. Organizational memory is a collective recollection of the past that is embedded within firm culture, procedures, and expertise. The findings demonstrate potential tradeoffs to linking versus locking into the firm's past, particularly in turbulent environments. By decomposing organizational memory's effects, this paper explains how organizational memory can both enable and constrain marketing implementation.
\end{abstract}

Keywords Marketing implementation · Organizational memory · Firm performance

Our understanding of organizational performance has focused considerably on a firm's current capabilities to understand and satisfy customer needs (e.g., Day 1994; Vorhies and Morgan 2005) but has not considered how these capabilities are a product of the firm's past. This study examines components of organizational memory that enable the implementation of marketing strategies that result in marketbased advantages. Researchers have only begun to examine the enabling role of knowledge and experience in marketing capability attainment (Hanvanich et al. 2006; Jayachandran et al. 2004; Morgan et al. 2003). This paper seeks to broaden our understanding of memory's role in marketing implementation. Pursuing this objective will serve to isolate mnemonic mechanisms that enable and constrain a firm's marketing implementation capability, which is defined as the superior ability to transform marketing strategies into resource deployments. 
Organizational performance is dependent upon the successful implementation of strategy (Bonoma 1985; Walker and Ruekert 1987). Given that the best-made plans can fail due to poor implementation and that such failures may hide the appropriateness of the chosen strategy (Bonoma 1985) heightens the need for marketing implementation research (cf. Noble 1999 for a review of the implementation literature). Prior studies posit that effective implementation is contingent on managerial behaviors and organizational structure (Bonoma and Crittenden 1988) and have empirically linked successful implementation to managerial commitment and communication (Noble and Mokwa 1999; Rapert et al. 2002), strategic behavior (Dobni and Luffman 2003; Homburg et al. 2004; Olson et al. 2005), and organizational structure (Slater and Olson 2001; Vorhies and Morgan 2003), and yet, our understanding of the influence of organizational memory on marketing implementation is relatively nascent, despite recognition of memory's importance and past calls for research (e.g., Day 1994; Sinkula 1994). While drawing on memory may reduce the risk of repeating past failures, it also introduces the possibility of continual repetition of past successes that are suboptimal in changing environments. This paper explores this paradox by examining the relationship between a firm's memory and its marketing implementation capability. It also addresses the issue of firm adaptation by empirically testing differing effects of memory on the firm's ability to transform marketing resources in dynamic and stable environments.

\section{Conceptual model}

A marketing implementation capability gauges the firm's ability to successfully execute strategy through the configuration and deployment of marketing resources (Noble and Mokwa 1999; Vorhies and Morgan 2005). Capabilities are collective activities through which the firm develops, integrates, and deploys internal and external resources (Day 1994; Zollo and Winter 2002). By enhancing the firm's ability to effectively configure resources to better respond in a changing environment (Eisenhardt and Martin 2000), capabilities contribute to a firm's ability to build and sustain a competitive advantage (Day 1994; Teece et al. 1997). As such, a marketing implementation capability provides for a superior ability to transform marketing strategies into resource deployments. Unresolved is an understanding of the mechanisms that shape this capability, particularly under different levels of environmental turbulence.

Capabilities are shaped through learning processes (Zollo and Winter 2002). Learning in organizations is "routine-based, history-dependent, and target-oriented" (Levitt and March 1988, p. 319). To make use of learning, organizations depend on memory (Huber 1991), which is information about past successes and failures that is retained by individuals and stored as routines, e.g., procedures, strategies, schemas, and culture (Levitt and March 1988; Walsh and Ungson 1991). Routines represent repetitive, interdependent patterns among multiple actors (Feldman and Pentland 2003). Routines embed past adaptation activities and thus enable quick, consistent results (Cohen and Bacdayan 1994); however, reliance can also be suboptimal by locking-in decision rules that dissuade the acquisition of new lessons that may be a 
necessary component to continued learning (Sinkula 1994). In this way, memory produces blinders that hinder learning and compromise strategic decisions (Biyalogorsky et al. 2006).

Questions remain concerning the mechanisms that allow for the application of marketing capabilities as well as the relationship between these mechanisms and market effectiveness. This study explores the role of three mnemonic mechanisms (i.e., culture, procedures, and expertise) on marketing implementation. Each mechanism is a connection to the past that is embedded in memory and proximal to attainment of the capabilities through which the organization engages its environment. This environmental engagement, operationalized as marketing implementation, mediates the relationship between memory and market effectiveness. The following discussion, as illustrated in Fig. 1, explores each mechanism and its relationship to marketing implementation under both low and high levels of environmental turbulence. Additionally, the relationship between marketing implementation and market effectiveness is empirically tested.

\subsection{Mnemonic mechanisms of marketing implementation}

Organizational culture is a learned pattern of perceiving, thinking, and feeling about problems of adaptation and coordination (Schein 1984) and is transmitted to provide meaning that aids organizational functioning (Deshpandé and Webster 1989). In this light, culture is an embodiment of memory (Walsh and Ungson 1991). Market orientation, consisting of beliefs that place emphasis on the market and serve to guide sensemaking and action (Deshpandé et al. 1993), is a cultural construction that has proven successful as a means of adaptation and coordination. In other words, firms assume a market focus because doing so has proven advantageous in the past. While the positive relationship between a market orientation and performance is firmly established (Kirca et al. 2005), this success is based largely on the firm's ability to apply its market focus in the attainment of organizational capabilities from which customers receive superior benefit (Day 1994). A market orientation alone will not lead to higher performance; rather, it serves to inform marketing implementation, which is ultimately judged by the market. Effective marketing

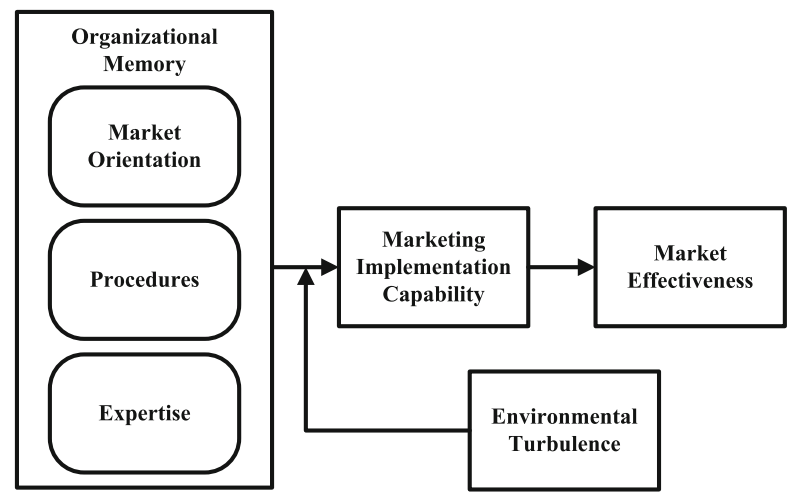

Fig. 1 Linking organizational memory to market effectiveness 
implementation requires strong identity and direction (Bonoma 1985). A market orientation provides this by focusing the firm's attention on a specific target, the market.

$\mathrm{H}_{1}$ : The greater the level of market orientation, the greater the marketing implementation capability

While several authors argue that routines combine to form capabilities (Morgan et al. 2003; Zollo and Winter 2002), a distinction is necessary between behaviors that are informed by expertise and those that follow procedure. Expertise resides within individuals and is the accumulation of skills and knowledge, while procedures are institutionalized lessons derived from past experience that predetermine the implementation of activities but do not contain explanations (Walsh and Ungson 1991). To produce consistent results, operational activities (e.g., purchasing, production, and order fulfillment) rely on regular and predictable behavior; however, strategic situations (e.g., marketing planning, product development, and marketing implementation) require an influx of variation. The effective transformation of strategy into resource deployments requires an open system that conforms to situational demands (Olson et al. 2005; Vorhies and Morgan 2003), whereas rote patterns run counter to marketing implementation success (Bonoma 1985). Organizations that rely on procedures may find it difficult to deviate from preexisting patterns, as similarly described by Dougherty (1992) in product development teams and Slotegraaf and Dickson (2004) in marketing planning.

$\mathrm{H}_{2}$ : The greater the use of procedures, the lower the marketing implementation capability

Expertise is contained within the skills and knowledge of decision makerswith skills enabling the application of knowledge toward the implementation of an appropriate response. Collective expertise provides greater input to bear on the situation based on the interactive contributions of individuals (Hambrick et al. 1996). Marketing expertise provides the collective insight about what worked and why and can translate into an effective implementation capability (Jayachandran et al. 2004; Morgan et al. 2003), innovativeness (Hanvanich et al. 2006), and immediate financial performance of new products (Moorman and Miner 1997). Expertise aids implementation, as decision makers are better able to frame the situation within its historical context and gauge the similarities and differences between past and present situations (Walsh and Ungson 1991). Thus, expertise embodies the skill and knowledge necessary to engage in effective implementation.

$\mathrm{H}_{3}$ : The greater the level of expertise, the greater the marketing implementation capability

\subsection{Moderating effect of environmental turbulence}

Under conditions of shifting customer demands and competitive threats, maintaining a market orientation becomes increasingly beneficial. Market attunement enables the 
effective configuration and deployment of marketing resources (Day 1994). Attention to market issues allows the firm to continuously align internal resources to match shifting opportunities or threats. By doing so, a market orientation serves to enhance the effectiveness of resource alignment under dynamic market conditions. Thus, by maintaining a market orientation, an organization manages problems of adaptation by focusing on the market, and through this, focus is better able to configure and deploy internal marketing resources.

$\mathrm{H}_{4 \mathrm{a}}$ : The greater the level of environmental turbulence, the stronger the positive relationship between a market orientation and a marketing implementation capability

Reliance on procedures for strategic processes that require openness can be detrimental. This negative effect is particularly pronounced in turbulent situations. A formulaic approach may lead to inappropriate action particularly in changing environments. Adaptive execution conforms to real-time demands, whereas procedures are based on historic situations that may not accurately reflect the current situation. Similar effects have been proposed for strategic decision making (Bourgeois and Eisenhardt 1988) and new product development (Moorman and Miner 1998). With greater turbulence, increased use of procedures that were developed under different environmental constraints further reduces the effectiveness of marketing implementation.

$\mathrm{H}_{4 \mathrm{~b}}$ : The greater the level of environmental turbulence, the stronger the negative relationship between procedures and a marketing implementation capability

Turbulent environments are information intensive (cf. Glazer 1991), where existing stocks of skills and knowledge are both challenged and supplanted. In turbulent environments, expertise may not translate as effectively due to a lack of relevancy. Specifically, evolving situations may challenge proven skills and knowledge that do not readily fit with new environmental demands. Hanvanich and colleagues (2006) demonstrate that the positive effect of memory (in terms of knowledge and familiarity) on organizational outcomes is weaker under turbulent conditions. Thus, the positive link between expertise and implementation is expected to be weaker in turbulent environments.

$\mathrm{H}_{4 \mathrm{c}}$ : The greater the level of environmental turbulence, the weaker the positive relationship between expertise and a marketing implementation capability

\subsection{Marketing implementation and market effectiveness}

Marketing implementation is crucial to firm performance (Morgan et al. 2003; White et al. 2003) and is expected to mediate the relationship between organizational memory and market effectiveness. The firm's ability to accomplish market-based goals is dependent upon successful implementation of its marketing strategy (Bonoma 1985). Market-based advantages are achieved through superior coordination and application of organizational capabilities (Day 1994; Day and Wensley 1988). A marketing implementation capability, as a dynamic capability (Eisenhardt and Martin 2000), should adapt to market conditions. Therefore, the effective 
deployment of marketing resources will result in the attainment of market-based goals.

$\mathrm{H}_{5}$ : A marketing implementation capability is positively related to market effectiveness

\section{Method}

To test the hypotheses, multi-item measures based on established scales were used for each of five constructs. To assess the measures and test the hypotheses, data were gathered from business executives. Unidimensionality was assessed by examining the interrelations among each scale's items using item-to-scale correlations and by conducting confirmatory factor analysis. Structural equation modeling was employed to test the hypotheses.

\subsection{Measures}

Market orientation, as developed by Deshpandé et al. (1993), is defined as the set of beliefs that place a premium on the market. The procedures measure gauges the degree to which there are predefined methods for marketing implementation and was adapted from Moorman and Miner's (1998) measure of organizational memory. The expertise measure, adapted from Celly and Frazier (1996), captures the extent to which the firm has skills and knowledge relating to marketing implementation. Marketing implementation capability assesses the degree to which the firm effectively deploys marketing resources based on intended marketing strategies. The measure was developed by Vorhies and Morgan (2005). Also based on Vorhies and Morgan (2005), market effectiveness measures the degree to which market-based goals have been met. The moderator, environmental turbulence, is a composite measure gauging perceptions of change in the customer and competitive dimensions of the firm's task environment (Jaworski and Kohli 1993). Table 1 contains the scale content and sources.

\subsection{Data collection}

Data were gathered by surveying business executives from a variety of industries with offices located in a west coast state. The sample of 600 businesses was derived from an extensive list provided by the state's trade office. The goal was to receive responses from a diverse set of industries, which should provide a robust test of theory. The survey was directed at executives actively involved in strategic marketing decision making. In order to maximize response rate, the data collection was multimodal. First, a prenotification letter followed by an email message was sent to 600 businesses directing respondents to an online survey. A total of 55 individuals completed the web-based survey. Next, three mailings - two letters with a questionnaire and one reminder postcard-were sent to nonrespondents. In total, 128 organizations participated in the research for a response rate of $21.3 \%$.

Each respondent acted as a key informant for his/her organization by reporting on the business as a whole or in regards to the business unit in larger organizations. To be 
Table 1 Scale content and sources

\begin{tabular}{|c|c|c|}
\hline Construct & Content of scale items & Source \\
\hline $\begin{array}{l}\text { Marketing } \\
\text { implementation } \\
\text { capability }^{\mathrm{a}}\end{array}$ & $\begin{array}{l}\text { Allocating resources, organizing marketing programs, } \\
\text { translating strategies into action, executing strategies } \\
\text { quickly }\end{array}$ & $\begin{array}{l}\text { Vorhies and } \\
\text { Morgan } 2005\end{array}$ \\
\hline Market effectiveness $^{\mathrm{a}}$ & $\begin{array}{l}\text { Market share growth relative to competitors, growth in } \\
\text { sales revenue, acquiring new customers, increasing sales } \\
\text { to existing customers }\end{array}$ & $\begin{array}{l}\text { Vorhies and } \\
\text { Morgan } 2005\end{array}$ \\
\hline Market orientation $^{\mathrm{b}}$ & $\begin{array}{l}\text { Customer service, good market information, knowledge } \\
\text { of competitors, customer value, customer focus, product } \\
\text { differentiation }{ }^{\mathrm{c}} \text {, customers first }{ }^{\mathrm{c}} \text {, best products }{ }^{\mathrm{c}} \text {, } \\
\text { primary business is serving customers }{ }^{\mathrm{c}}\end{array}$ & $\begin{array}{l}\text { Deshpandé } \\
\text { et al.1993 }\end{array}$ \\
\hline Procedures ${ }^{\mathrm{b}}$ & $\begin{array}{l}\text { Standard approach, well-defined procedure, established } \\
\text { procedures, developed routines }\end{array}$ & $\begin{array}{l}\text { Moorman and } \\
\text { Miner } 1998\end{array}$ \\
\hline Expertise $^{\mathrm{b}}$ & $\begin{array}{l}\text { Great deal of knowledge, strong skills, great deal of } \\
\text { experience, developed skills and activities }\end{array}$ & $\begin{array}{l}\text { Celly and } \\
\text { Frazier } 1996\end{array}$ \\
\hline $\begin{array}{l}\text { Environmental } \\
\text { turbulence }^{b}\end{array}$ & $\begin{array}{l}\text { Changing customer preferences, customers seek new } \\
\text { products, new customers with different needs, cutthroat } \\
\text { competition, promotional wars, readily matched } \\
\text { offering, price competition, new competitive moves }\end{array}$ & $\begin{array}{l}\text { Jaworski and } \\
\text { Kohli } 1993\end{array}$ \\
\hline
\end{tabular}

\footnotetext{
${ }^{\text {a }}$ Seven-point much worse/much better to others in industry

${ }^{\mathrm{b}}$ Seven-point agree/disagree scale

${ }^{\mathrm{c}}$ Item removed
}

included in the study, respondents had to hold a management level position and be actively involved in strategic marketing decisions (score of four or higher on a sevenpoint strategic involvement scale). Given these requirements, ten respondents were removed from the study, leaving 118 usable responses (usable response rate of 19.7\%). The remaining informants represented a broad mix of industries (47\% services, $30 \%$ manufacturing, and $23 \%$ other). Respondents were executives (44\% chief executive officer, $25 \%$ vice president, and $31 \%$ middle management) with an average of 8 years of experience in the organization and were highly involved in strategic decisions (average of 6.0 on a seven-point scale). To test for bias, mean differences were examined among online, early and late returns. No differences were observed; therefore, nonresponse bias did not appear to be an issue (cf. Armstrong and Overton 1977).

\section{Results}

\subsection{Measurement model results}

Item-to-scale correlations were examined and only items with correlations exceeding 0.40 were retained (Churchill 1991). Next, the constructs were modeled as first-order factors in LISREL VIII using the covariance matrix as input. This allowed for examination of both within- and across-factor loadings and measurement error. Given the limited sample size, the factors were modeled in two related sets. Based on this procedure, four market orientation items were trimmed after consideration 
Table 2 Descriptive statistics, reliabilities, and correlations

\begin{tabular}{|c|c|c|c|c|c|c|c|c|c|}
\hline & \multirow[t]{2}{*}{ Mean } & \multirow[t]{2}{*}{$\begin{array}{l}\text { Standard } \\
\text { deviation }\end{array}$} & \multirow[t]{2}{*}{$\begin{array}{l}\text { Composite } \\
\text { reliability }\end{array}$} & \multirow[t]{2}{*}{ AVE } & \multicolumn{5}{|c|}{$\begin{array}{l}\text { Correlations among latent } \\
\text { constructs }\end{array}$} \\
\hline & & & & & 1 & 2 & 3 & 4 & 5 \\
\hline $\begin{array}{l}\text { (1) Marketing } \\
\text { implementation } \\
\text { capability }\end{array}$ & 4.20 & 1.21 & 0.91 & 0.72 & 1.00 & & & & \\
\hline $\begin{array}{l}\text { (2) Market } \\
\text { effectiveness }\end{array}$ & 4.86 & 1.09 & 0.84 & 0.57 & 0.34 & 1.00 & & & \\
\hline (3) Market orientation & 4.98 & 0.92 & 0.77 & 0.40 & 0.45 & 0.35 & 1.00 & & \\
\hline (4) Procedures & 4.23 & 1.19 & 0.84 & 0.59 & 0.15 & 0.04 & 0.37 & 1.00 & \\
\hline (5) Expertise & 5.27 & 1.14 & 0.91 & 0.73 & 0.57 & 0.25 & 0.50 & 0.37 & 1.00 \\
\hline
\end{tabular}

that the domain of the construct would not be compromised. The fit for each model is as follows: endogenous $\left(\chi^{2}=58.38\right.$ with $19 d f$; standardized root mean square residual $(\mathrm{SRMR})=0.06$; Tucker-Lewis index $(\mathrm{TLI})=0.90$; comparative fit index $(\mathrm{CFI})=0.93)$ and exogenous $\left(\chi^{2}=117.58\right.$ with $62 d f$; SRMR $=0.07$; TFI $=0.91$; $\mathrm{CFI}=$ 0.93). Table 2 reports descriptive statistics, reliabilities, and correlations.

The measurement model results indicate that each estimated model adequately represented the observed input matrix (i.e., covariance matrix) for both the endogenous and exogenous set of constructs. Composite reliability estimates ranged from 0.77 to 0.91 and average variance extracted (AVE) estimates ranged from 0.40 to 0.73 . Discriminant validity was supported in all cases, as the square of the parameter estimate (phi) between each pair of constructs was less than the average AVE for the pair (Fornell and Larcker 1981).

\subsection{Structural model results}

To control for measurement error, each loading estimate (lambda) was fixed as the square root of the reliability estimate, and the error term (theta) was set to one minus the reliability (Hair et al. 2006). The overall fit of the structural model was acceptable $\left(\chi^{2}=7.20\right.$ with 3 df; SRMR $=0.05$; TFI $=0.89$; CFI $\left.=0.97\right)$, and all paths are statistically significant (see Table 3 ). The structural equations account for $47 \%$ of

Table 3 Structural model results: completely standardized path estimates

\begin{tabular}{lrr}
\hline Hypotheses: path & Estimate & tvalue \\
\hline $\mathrm{H}_{1}$ : Market orientation $\rightarrow$ marketing implementation capability & 0.32 & 2.58 \\
$\mathrm{H}_{2}$ : Procedures $\rightarrow$ marketing implementation capability & -0.19 & -1.91 \\
$\mathrm{H}_{3}$ : Expertise $\rightarrow$ marketing implementation capability & 0.52 & 4.66 \\
$\mathrm{H}_{5}$ : Marketing implementation capability $\rightarrow$ market effectiveness & 0.40 & 4.04
\end{tabular}

$t$ values of 1.65 or greater are significant at the 0.05 level; $t$ values of 2.33 or greater are significant at the 0.01 level 
the variance in marketing implementation and $16 \%$ of the variance in market effectiveness. The independent effects $\left(\mathrm{H}_{1}-\mathrm{H}_{3}\right.$ and $\left.\mathrm{H}_{5}\right)$ are fully supported based on model fit, path significance, and variance explained.

To test for moderation, a multigroup analysis was conducted for both low and high levels of environmental turbulence, based on two groups formed using cluster analysis (cf. Hair et al. 2006). To determine group membership, the summed items for market turbulence and competitive intensity were input into a cluster analysis. Using Ward's method, a two-group solution was confirmed based on a large increase in the agglomeration coefficient, which indicated a heterogeneous combination when forming a single group. This solution was used to test for the moderating effect of environmental turbulence using structural equation modeling. The fit of the model with all hypothesized paths estimated freely was acceptable $\left(\chi^{2}=9.73\right.$ with $6 d f$; $\mathrm{SRMR}=0.08$; TLI=0.91; CFI=0.97). The model was then re-estimated constraining a single path to equality between the low and high environmental turbulence groups. Table 4 presents the chi-square difference test results, which indicated that the marketing implementation relationship was stronger in the high environmental turbulence group for both market orientation $\left(\mathrm{H} 4 \mathrm{a} ; \chi_{\text {diff }}^{2}=10.09\right)$ and procedures $\left(\mathrm{H} 4 \mathrm{~b} ; \chi_{\text {diff }}^{2}=11.04\right)$ but not for expertise $\left(\mathrm{H} 4 \mathrm{c} ; \chi_{\text {diff }}{ }^{2}=2.41\right)$. This suggests that the effects of market orientation and procedures on marketing implementation capability statistically differ between low and high turbulent environments.

\section{Discussion}

Marketing capabilities capture the collective ability to develop, integrate, and deploy internal and external resources in the attainment of a sustainable advantage. To be amenable to adaptation in dynamic situations, these capabilities must evolve in a changing environment, and yet, capabilities represent learned ways of thinking and behaving that are rooted in the past. Based on the findings, effective marketing implementation requires that the firm define success in terms of customer value and maintain systems that retain what was learned from past successes without being locked into procedures. Firms that codify history into practice are rigid and inflexible, which dampens the effectiveness of resource alignment to market demands particularly in highly turbulent environments. When the firm is operating in static environments, expertise is an important ingredient to successful marketing resource deployment, while turbulent environments demand expertise mixed with a market focus and avoidance of rote marketing resource deployment.

Table 4 Structural model results: moderating effect of environmental turbulence

\begin{tabular}{lcrr}
\hline & Low & High & $\chi_{\text {diff }}^{2}(1 d f)$ \\
\hline $\mathrm{H}_{4 \mathrm{a}}:$ Market orientation $\rightarrow$ marketing implementation capability & 0.04 & 0.96 & 10.09 \\
$\mathrm{H}_{4 \mathrm{~b}}$ : Procedures $\rightarrow$ marketing implementation capability & 0.08 & -0.65 & 11.04 \\
$\mathrm{H}_{4 \mathrm{c}}$ : Expertise $\rightarrow$ marketing implementation capability & 0.65 & 0.28 & 2.41 \\
\hline
\end{tabular}

$\chi_{\text {diff }}^{2}$ values of 3.84 or greater are significant at the 0.05 level 
These results would suggest that firms should invest in skill and knowledge accumulation. The tacit nature of expertise requires a deliberative learning process of experimenting, sharing, and retaining the performance implications of past efforts (Lynn et al. 1997; Zollo and Winter 2002). As the results indicate, this form of experiential learning translates into market-based advantages that are socially complex and inimitable (Teece et al. 1997). The key is accumulation of expertise without establishing procedures that constrain flexibility (Leonard-Barton 1992). In this way, the experienced firm is able to address strategic market issues in a nonepisodic, nonstatic manner (Mankins and Steele 2006) by emphasizing the desired ends without dictating the means. This becomes increasingly important in a turbulent environment, wherein firms must rapidly make sense of the market in order to expeditiously configure resources toward satisfying customers.

The results of this paper lend additional support to the role of market orientation in resolving the capability-rigidity paradox (Atuahene-Gima 2005). Maintaining a market focus while drawing from expertise facilitates the integration and alignment of capabilities that transform marketing resources into valued outputs. While prior studies offer contradictory evidence as to the moderating effect of environmental turbulence on the market orientation-performance relationship (cf. Kirca et al. 2005), this study's results support the environment's influence on market orientation's effect on marketing implementation. This suggests that a market orientation enhances the effectiveness of resource alignment under dynamic market conditions. In turbulent environments, marketing implementation should be a fluid process guided by market issues and expertise, not predetermined by rubric.

The results also suggest that success may lead to existing procedures-reinforced through past successes - that inhibit effective marketing implementation. In such a case, a marketing manager continues with familiar approaches when new environments may demand a unique response. Procedures - which are embedded in the organization and not individuals - do not retain knowledge of cause-and-effect relationships. In a shifting environment, this link may be severed. As such, procedures are closed and stable processes that restrict the organization and reinforce the status quo (Argyris and Schon 1978) and may be maladaptive under shifting market conditions. Given that strategy formation and implementation are interdependent and locked in a recursive relationship (Cespedes 1991; Sashittal and Jassawalla 2001) exacerbates this situation. The organization needs to develop the ability to refine memory in order to effectively respond to new situations. This may best be accomplished by developing learning routines that allow the firm to learn to learn and unlearn - either through experimentation to increase the variety of experiences or through target-oriented approaches that allow room for improvisation. The firm should be flexible in how it deploys its accumulated skills and knowledge and mindful in its use of procedures. Ultimately, the management of memory is critical to marketing implementation.

\subsection{Study limitations}

This paper has limitations that should be acknowledged. While market orientation is internally consistent, the amount of variance captured by the scale items was relatively low. Given the broad nature of the market orientation construct to include 
customers and competitors, representative items were retained so as to not compromise the face validity of the target construct. An additional limitation is that a firm's marketing implementation capability captures less than $20 \%$ of the variance in market effectiveness. This suggests the degree to which market effectiveness remains unexplained by a firm's ability to successfully execute strategy.

\subsection{Implications and future research}

As demonstrated here, there are tradeoffs to organizational memory. By linking to the past, memory may reduce variability, wherein the firm focuses exclusively on exploitation of what is currently known rather than the exploration of what could be (March 1991). This relationship of memory to the exploitation of the known versus the exploration of the unknown presents a paradox in need of further study. For example, how does the firm reconcile and support tactical capabilities that rely on procedures while not overexposing strategic capabilities that while benefiting from the past can ill afford to acquiesce to its full force? Additionally, what mechanisms enable the firm in a dynamic market to cobble segments of formerly successful routines into a new implementation procedure based on newly created, situationspecific experience?

The ability to manage paradox is increasingly recognized as an important organizational trait (Lewis 2000). Recent research addresses paradox resolution in new product development and marketing planning (Atuahene-Gima 2005; LeonardBarton 1992; Slotegraaf and Dickson 2004). Clearly, our understanding of paradoxical tension - as this paper demonstrates with organizational memoryrequires further development as the coexistence of contradictory structures, interpretations, and processes would seem to contain within them the basis for organizational transformation (Cameron and Quinn 1988). This is of particular importance to marketing scholars and managers as such transformation explains adaptation to market change.

\section{Conclusion}

Organizational memory influences the behaviors that affect performance. This study examines mnemonic mechanisms which translate into capabilities that result in market-based advantages. Distinctions are made between those mechanisms that facilitate marketing implementation and those that instill rigidity; such distinctions made stronger under different market conditions. Revealing these mechanisms contributes to a better understanding of the means to transform organizations into responsive entities that adapt in changing environments.

\section{References}

Argyris, C., \& Schon, D. A. (1978). Organizational learning: A theory of action perspective. Reading: Addison-Wesley. 
Armstrong, J. S., \& Overton, T. S. (1977). Estimating nonresponse bias in mail surveys. Journal of Marketing Research, 14(1), 396-402.

Atuahene-Gima, K. (2005). Resolving the capability-rigidity paradox in new product innovation. Journal of Marketing, 69(4), 61-83.

Biyalogorsky, E., Boulding, W., \& Staelin, R. (2006). Stuck in the past: Why managers persist with new product failures. Journal of Marketing, 70(2), 108-121.

Bonoma, T. V. (1985). The marketing edge: Making strategies work. New York: Free.

Bonoma, T. V., \& Crittenden, V. L. (1988). Managing marketing implementation. Sloan Management Review, 29(2), 7-14.

Bourgeois, L. J., \& Eisenhardt, K. M. (1988). Strategic decision processes in high velocity environments: four cases in the microcomputer industry. Management Science, 34(7), 816-835.

Cameron, K. S., \& Quinn, R. E. (1988). Organizational paradox and transformation. In R. E. Quinn \& K. S. Cameron (Eds.), Paradox and transformation: Toward a theory of change in organization and management (pp. 1-18). Cambridge: Ballinger.

Celly, K. S., \& Frazier, G. L. (1996). Outcome-based and behavior-based coordination efforts in channel relationships. Journal of Marketing Research, 33(2), 200-210.

Cespedes, F. V. (1991). Organizing and implementing the marketing effort: Text and cases. Reading: Addison-Wesley.

Churchill, G. A. (1991). Basic marketing research. Fort Worth: Dryden.

Cohen, M. D., \& Bacdayan, P. (1994). Organizational routines are stored as procedural memory: Evidence from a laboratory study. Organization Science, 5(4), 554-568.

Day, G. S. (1994). The capabilities of market-driven organizations. Journal of Marketing, 58(4), 37-52.

Day, G. S., \& Wensley, R. (1988). Assessing advantage: A framework for diagnosing competitive superiority. Journal of Marketing, 52(2), 1-20.

Deshpandé, R., Farley, J. U., \& Webster, F. E. (1993). Corporate culture, customer orientation, and innovativeness in Japanese firms: A quadrad analysis. Journal of Marketing, 57(1), 23-37.

Deshpandé, R., \& Webster, F. E. (1989). Organizational culture and marketing: Defining the research agenda. Journal of Marketing, 53(1), 3-15.

Dobni, C. B., \& Luffman, G. (2003). Determining the scope and impact of market orientation profiles on strategy implementation and performance. Strategic Management Journal, 24, 577-585.

Dougherty, D. (1992). Interpretive barriers to successful product innovation in large firms. Organization Science, 3(2), 179-202.

Eisenhardt, K. M., \& Martin, J. A. (2000). Dynamic capabilities: What are they? Strategic Management Journal, 21, 1105-1121.

Feldman, M. S., \& Pentland, B. T. (2003). Reconceptualizing organizational routines as a source of flexibility and change. Administrative Science Quarterly, 48, 91-118.

Fornell, C., \& Larcker, D. F. (1981). Evaluating structural equation models with unobservable variables and measurement error. Journal of Marketing Research, 18(1), 39-50.

Glazer, R. (1991). Marketing in an information-intensive environment: strategic implications of knowledge as an asset. Journal of Marketing, 55(4), 1-19.

Hair, J. F., Black, W. C., Babin, B. J., Anderson, R. E., \& Tatham, R. L. (2006). Multivariate data analysis, 6/e. Upper Saddle River: Pearson Prentice Hall.

Hambrick, D. C., Cho, T. S., \& Chen, M. (1996). The influence of top management team heterogeneity on firms' competitive moves. Administrative Science Quarterly, 41, 659-684.

Hanvanich, S., Sivakumar, K., \& Hult, G. T. M. (2006). The relationship of learning and memory with organizational performance: The moderating role of turbulence. Journal of the Academy of Marketing Science, 34(4), 600-612.

Homburg, C., Krohmer, H., \& Workman, J. P. (2004). A strategy implementation perspective of market orientation. Journal of Business Research, 57(12), 1331-1340.

Huber, G. P. (1991). Organizational learning: The contributing processes and the literatures. Organization Science, 2(1), 88-115.

Jayachandran, S., Hewett, K., \& Kaufman, P. (2004). Customer response capability in a sense-and-respond era: The role of customer knowledge process. Journal of the Academy of Marketing Science, 32(3), 219-233.

Jaworski, B. J., \& Kohli, A. K. (1993). Market orientation: Antecedents and consequences. Journal of Marketing, 57(3), 53-70.

Kirca, A. H., Jayachandran, S., \& Bearden, W. O. (2005). Market orientation: A meta-analytic review of its antecedents and impact on performance. Journal of Marketing, 69(2), 24-41. 
Leonard-Barton, D. (1992). Core capabilities and core rigidities: A paradox in managing new product development. Strategic Management Journal, 13, 111-125.

Levitt, B., \& March, J. G. (1988). Organizational learning. American Review of Sociology, 14, 319-340.

Lewis, M. W. (2000). Exploring paradox: Toward a more comprehensive guide. Academy of Management Review, 25(4), 760-776.

Lynn, G. S., Simpson, J. T., \& Souder, W. E. (1997). Effects of organizational learning and informationprocessing behaviors on new product success. Marketing Letters, 8(1), 33-39.

Mankins, M. C., \& Steele, R. (2006). Stop making plans; start making decisions. Harvard Business Review, 84(1), 76-84.

March, J. G. (1991). Exploration and exploitation in organizational learning. Organization Science, 2(1), 71-87.

Moorman, C., \& Miner, A. S. (1998). The convergence of planning and execution: Improvisation in new product development. Journal of Marketing, 62(3), 1-20.

Moorman, C., \& Miner, A. S. (1997). The impact of organizational memory on new product performance and creativity. Journal of Marketing Research, 34(1), 91-106.

Morgan, N. A., Zou, S., Vorhies, D. W., \& Katsikeas, C. S. (2003). Experiential and informational knowledge, architectural marketing capabilities, and the adaptive performance of export ventures: A cross-national study. Decision Sciences, 34(2), 287-321.

Noble, C. H. (1999). The eclectic roots of strategy implementation research. Journal of Business Research, 45(2), 119-134.

Noble, C. H., \& Mokwa, M. P. (1999). Implementing marketing strategies: Developing and testing a managerial theory. Journal of Marketing, 63(4), 57-73.

Olson, E. M., Slater, S. F., \& Hult, G. T. M. (2005). The performance implications of fit among business strategy, marketing organization structure, and strategic behavior. Journal of Marketing, 69(3), 49-65.

Rapert, M. I., Velliquette, A., \& Garretson, J. A. (2002). The strategic implementation process: Evoking strategic consensus through communication. Journal of Business Research, 55(4), 301-310.

Sashittal, H. C., \& Jassawalla, A. R. (2001). Marketing implementation in smaller organizations: Definition, framework, and propositional inventory. Journal of the Academy of Marketing Science, 29 (1), 50-69.

Schein, E. H. (1984). Coming to a new awareness of organizational culture. Sloan Management Review, 25(2), 3-16.

Sinkula, J. M. (1994). Marketing information processing and organizational learning. Journal of Marketing, 58(1), 35-45.

Slater, S. F., \& Olson, E. M. (2001). Marketing's contribution to the implementation of business strategy: An empirical analysis. Strategic Management Journal, 22, 1055-1067.

Slotegraaf, R. J., \& Dickson, P. R. (2004). The paradox of a marketing planning capability. Journal of the Academy of Marketing Science, 32(4), 371-385.

Teece, D. J., Pisano, G., \& Shuen, A. (1997). Dynamic capabilities and strategic management. Strategic Management Journal, 18, 509-533.

Vorhies, D. W., \& Morgan, N. A. (2005). Benchmarking marketing capabilities for sustainable competitive advantage. Journal of Marketing, 69(1), 80-94.

Vorhies, D. W., \& Morgan, N. A. (2003). A configuration theory assessment of marketing organization fit with business strategy and its relationship with marketing performance. Journal of Marketing, 67(1), $100-115$

Walker, O. C., \& Ruekert, R. W. (1987). Marketing's role in the implementation of business strategies: A critical review and conceptual framework. Journal of Marketing, 51(3), 15-33.

Walsh, J. P., \& Ungson, G. R. (1991). Organizational memory. Academy of Management Review, 16(1), 57-91.

White, J. C., Conant, J. S., \& Echambadi, R. (2003). Marketing strategy development styles, implementation capability, and firm performance: Investigating the curvilinear impact of multiple strategy-making styles. Marketing Letters, 14(2), 111-124.

Zollo, M., \& Winter, S. G. (2002). Deliberate learning and the evolution of dynamic capabilities. Organization Science, 13(3), 339-351. 